\title{
Evaluating the habitat factors of Pristiphora laricis Infestation:
}

\section{Information Load Model}

\author{
Shuhan Wang ${ }^{1,}$, Bingbing Zeng ${ }^{2, b}$ and Xiaoli Zhang ${ }^{3, c}$ \\ ${ }^{1}$ QsingHua East Road No.35, Beijing Forestry University, China \\ ${ }^{2}$ The people's government in HePing town, ChangXing county in ZheJiang Province, China \\ ${ }^{3}$ QsingHua East Road No.35, Beijing Forestry University, China

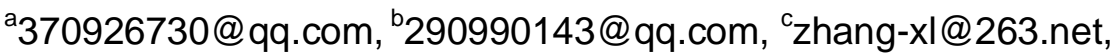

Keywords: Pristiphora laricis; relationship; habitat factors; GIS-information load model;

Abstract. Larch defoliation by Pristiphora laricis has caused great damage in China. Taking Saihanba Mechanical Forestry Farm of Hebei Province between 2007 and 2010 as the study area, the relationship between the Pristiphora laricis infestation and the habitat factors were analyzed after representative needles and environmental factors were collected. PD (the population density per tree), PIIT (percentage of insect-infected trees in one sample plot) and IA (infected area) were identified as dependent variables to measure the degree of infection. The conclusions are as follows: PD and PIIT have significant differences in areas with different species composition; Canopy density and stand density have a negative correlation with PD; Pristiphora laricis will not infect young growth and it has a tendency to spread to high altitude. At last, in order to provide basis for macro prevention and controlling of insect attack, habitat factors which are closely related to the occurrence of insect attack are input into information load GIS model to estimate the damages caused by insect infection.

\section{Introduction}

Anthropogenic activities, forest fires, and insect attack are the three primary obstacles for forest sustainable development. Forest diseases and pest is considered as one of the typical biological and natural disasters and it becomes more and more serious. Forest insect epidemics like beetle, spruce budworm, tent caterpillar et al. can have severe ecological (changes in carbon content, climate deterioration), economic (reduction of timber supplies) and social (unemployment and crime rates increase) effects towards forest ecosystem by impeding growth of trees over extensive areas and even killing trees [1]. Result of spatial and temporal patterns of tree mortality can profoundly affect the structure and function of ecosystem. Impacts of insect outbreaks are enormous because they are of comparable magnitude to other global change factors like direct forest fire emissions [3]. Furthermore, the impacts would negate carbon gains from increased growth and rates of photosynthesis by climate warming, elevated atmospheric $\mathrm{CO} 2$ concentrations, and nitrogen deposition within the affected regions [4]. Unlike fires causing large direct emissions, the insect impacts forest carbon cycle indirectly by transferring of carbon from living biomass to dead organic matter, reducing net primary production (NPP) with subsequent increases in heterotrophic respiration, and changing forest succession and age-class structures [5]. Forest pests are one of the major factors affecting forest heath, and also affect the normal life of human beings as well. Pests and biological invasion have caused a lot of economic losses. Therefore, monitoring and accurate prediction to pests become an urgent problem to be solved for forestry authority. 
The most aggressive forest insect pest in North America is the mountain pine beetle that has attacked 14 million hectares. Forest pest in China also has become extremely severe since 1990s. The moderate or severe degree area affected by pests increased to 4, 267, 000 hectares nearly 80 percent to the area of plantation every year, which is much higher than the average level in the whole world [7]. Pristiphora laricis was first reported in China in 1990 [8] and the infection distributes in HeiLongjiang, Jilin, Hebei and Shanxi province. Larix gmelinii, Larix olgensis and Larix principis-rupprechtii is the main feeding object and host for the larva [8]. It is also the main destructive insect of larch plantation in Saihanba Mechanical Forest Farm of Hebei Province, China. Pristiphora laricis in Saihanba Mechanical Forest Farm reproduce at a rate of one generation per year. The sawfly unevenly distributes in elevations ranging from $1500 \mathrm{~m}$ to $2500 \mathrm{~m}$, and outbreak in larch forest under 1900m [9] . Pristiphora laricis belongs to Hymenoptera, Tenthredinidae, sawfly. The mature larva will cocoon in the litter layer and they will overwinter as prepupa. They will become adults in late May next year. The oviposition period would be in early June. The eggs, most of which are on the back of larch needles, are laid singly on the underside of them. Egg stage will be 8-10 days, with fecundity 35 78 eggs, spawning rate 96\%. The hatching would usually be in the morning. Larvae period will be 5 years. Begin feeding when 2 years old. Needles would be eaten with indentation of zigzag. The old needles will be destroyed after 3 years. Late August is the feeding peak, and also rampant occurance stage, because the whole needles can be eaten up. Mature larva will overwinter by cocooning underground.

Insect impacts on forest growth, function, structure, and carbon dynamics have generally been ignored in large-scale forest ecosystem studies, because data on insects covering large areas are expensive and hard to collect and high accuracy of monitoring are therefore not widely available [3] . Since 1930s, remote sensing approaches had been explored for detecting, mapping and monitoring forest disturbances of jack pine budworm defoliation [10], [11], spruce budworm defoliation [12], mountain pine beetle, [13], [14], Douglas-fir beetle [15], spruce beetle [16], gypsy moth [17], caterpillar [18] and pine moth [19].

Traditional method of pests' monitoring mainly based on sampling in the forest, investigating, and combining with other information in the field of pests' monitoring. It is not only time-consuming and wasting energy, but it also not provide spatiotemporal information of large scale area's monitoring quickly, which may affect the accuracy of prediction to a certain extent. Remote sensing and GIS technology is a non-destructive testing technology, with rapid, macroscopical and objective advantages. And there are not sufficient researches on Pristiphora laricis infection by GIS and RS in China. The main objective of this study was to describe the situation of spread of Pristiphora laricis's infection and improve the accuracy of prediction in the study area, through collecting climate, sample plots and topographic data combining technology of GIS and RS.

\section{Background}

At present, there were many mathematical models for spatial prediction analysis of pest disasters, mainly including statistical models, fuzzy math model, system model, expert system model, artificial neural network model and image recognition systems and so on. However, information load method combining external factors into one uniform indicator can be easily implemented in the GIS environment. Information load method has calculation formula of information load from information science, and its principle of calculation and formula derivation are simple. Its calculation factors have no limit, and the weight of each factor is directly calculated by the formula so that it could reduce subjective judgement of human. As a result, after several years development, in the field of disaster spatial forecasting, it was widely recognized. 
Pristiphora laricis disaster and its impact factors are closely related to spatial location, so with the GIS technology information load method could not only manage the information of pest disaster, but also analyze statistical relationship between the occurrence of pests and environmental factors from different spatial and temporal scales, and quantitatively assess and analyze the risk of pest disasters and their possible biohazard zone. It had great significance to pest monitoring and early warning, spatial forecasting and disaster prevention and mitigation.

Information load method was essentially a statistical analysis method. Some foreign scholars classified it to Double Variable Statistical Analysis method [20]. It combined the subjective experience of experts with GIS's objective data analysis ability well.

Information load used probability to calculate, and could use frequency to estimate conditional probability in actual calculations [21]. Using information load model to make spatial prediction to forest pests, it was mainly transforming measured value referring to various factors which affect the occurrence of pests, into the information load referring to the occurrence of the pests. In order to evaluate the extent of the pests and make spatial distribution maps of the occurrence trends of the pests, the contribution of various factors to the occurrence of the pests was expressed by using the information load with various factors reflecting the occurrence of the pests.

The generation of pest disasters $(Y)$ was influenced by a variety of factors $\left(X_{i}, i=1,2, \cdots, n\right)$, yet the importance and characteristics of each factor were not the same. In different natural environments, there was always a kind of "the best combination of factors" for the pest disaster, including the most essential influencing factors and the specific state of the factors. So, in the research of the pest, we could not remain in the study of individual factor only, but should make comprehensive study of "combination of pests' factors".

It is critical to obtain information of high quantity and quality in the forecast process to forecast the generation of pests disaster that is recognized to be measured by information load and as quantitative basis of the prediction. The principle is as follows.

$$
{ }_{I}\left(y, x_{1}, x_{2}, L x_{n}\right)=\log _{2} \frac{p\left\langle y \mid x_{1} x_{2} L x_{n}\right\rangle}{p(y)} \text {. }
$$

The above equation could also be written as the following equation.

$$
I\left(y, x_{1}, x_{2}, \mathrm{~L} x_{n}\right)=I\left(y, x_{1}\right)+I x_{1}\left(y, x_{2}\right)+\mathrm{L}+I x_{1} x_{2} \mathrm{~L} x_{n-1}\left(y, x_{n}\right) .
$$

In the (1) equation, $I\left(y, x_{1}, x_{2}, \ldots, x_{n}\right)$ presents combination of specific factors. $x_{1}, x_{2}, \ldots, x_{n}$ provide information load for the occurrence of pests.

$P\left(y \mid x_{1} x_{2} \ldots x_{n}\right)$ presents the probability of pest occurrence under the condition of combination of factors $x 1 \times 2 \ldots x 3$.

$P(y)$ presents the probability of pest occurrence.

$I x_{1}\left(y, x_{2}\right)$ presents the information load providing by factor $x_{2}$ for the occurrence of pests under the condition of factor $x_{1}$ existing.

Format (2) showed that the information load providing by the combination of factors $x_{1}, x_{2}, \ldots, x_{n}$ for occurrence of pest is equal to the sum of the information load provided by factor $x_{1}$ plus the information load providing by $x_{2}$ for the occurrence of pest after $x_{1}$ confirmed, until after $x_{1}, x_{2}, \ldots, x_{n-1}$ confirmed, plus information load providing by $x_{n}$ for the occurrence of pest, which could show that this kind of spatial evaluation fully consider the combined effect of different roles of factors.

\section{Study area}

Saihanba Mechanical Forestry Farm is located in the north of Weichang Manchu and Mongolian Autonomous Prefecture in Hebei Province. The area's latitude ranges from $42^{\circ} 02^{\prime}$ to $42^{\circ} 36^{\prime} \mathrm{N}$ or 58.6 kilometers, while its longitude spans from $116^{\circ} 51^{\prime}$ to $117^{\circ} 39^{\prime} \mathrm{E}$ or 65.6 kilometers. The bordering area 
is Inner Mongolia Keshiketeng Banner to the north and Duolun County to the west. It also borders YuDaoKou pasture in Hebei province to the south and Weichang County to the east. The study site is divided into two topographical regions: plateau and mountains. The former's elevations generally range from 1500 to $1939.6 \mathrm{~m}$. Sand soil is the mainly type and it also has both meadow soil and bog soil. This area is part of the southern end of the Inner Mongolia Plateau.

The forest is mainly composed of natural successive forest in the north of Hebei province, mainly such as birch (Betula platyphylla), aspen (Populus davidiana), north-china larch (Larix principis-rupprechtii), spruce (Picea meyeri), mongolian oak (Quercus mongolica). The area of plateau is in the south end of Mongolia Plateau, with vegetation varying from forests to grassland. There are not only the forests mentioned above, but also meadow and meadow steppe, such as tessellated meadow, Stipa baicalensis, Leymus chinensis, Filifolium sibiricum and so on [22]. The forest farm is semi-arid-sub-humid continental monsoon climate. In recent years, Pristiphora laricis has become a major pest damaging Saihanba Mechanical Forestry Farm of Hebei Province.

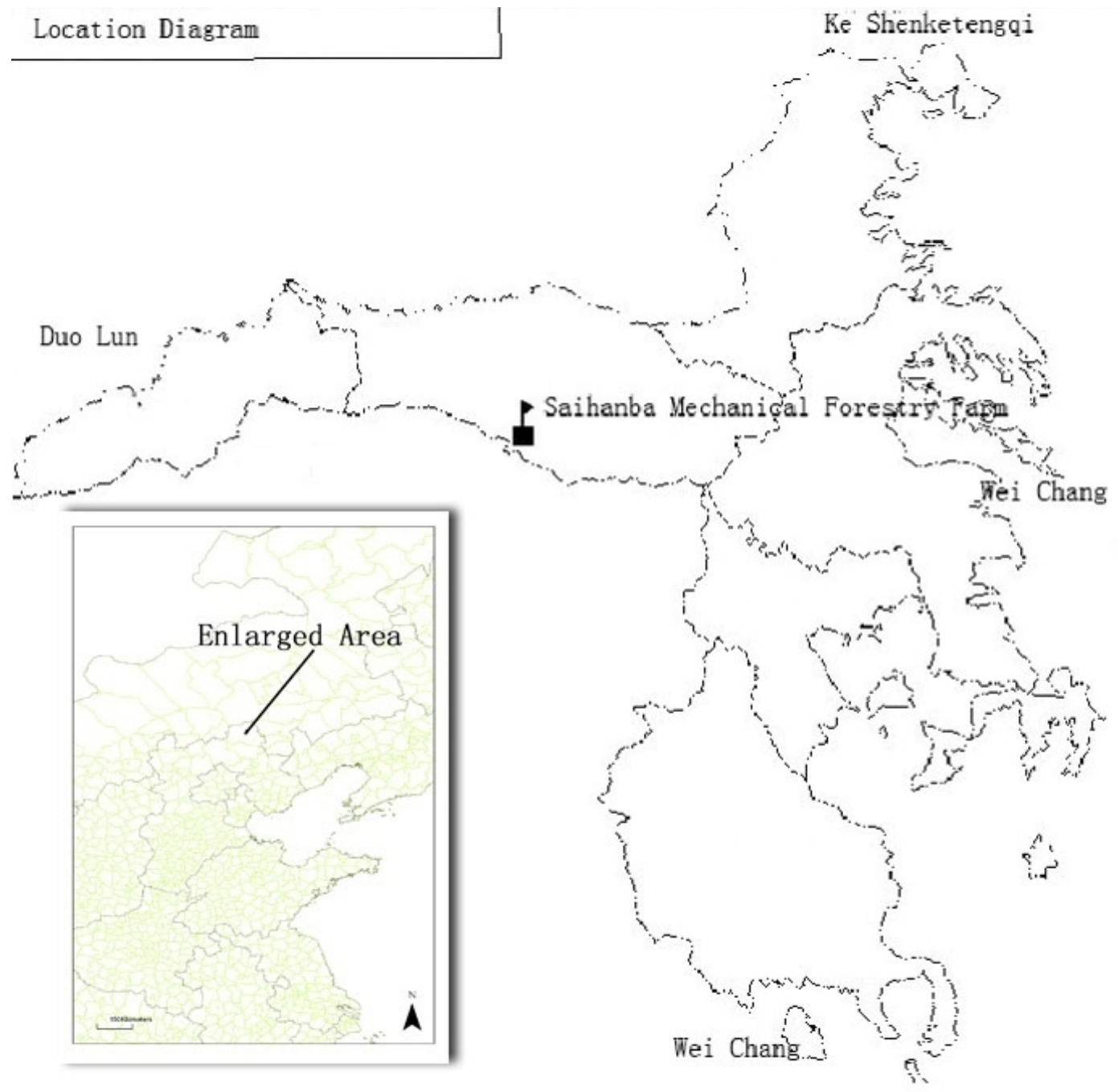

Figure 1. Geographical Position of Study Area 


\section{Method}

\section{Data collection}

At the beginning of August 2007, by using a simple random sampling, each sampling area with different damage degree were distributed with two fixed field sampling plots to a total of 10 and each of its scale is $20 \mathrm{~m} * 20 \mathrm{~m}$. Forestry site types should be considered when the plots were settled. Three sample plots in every level (pure forest level and mixed forest level) were selected to investigate PD and PIIT. Five standard trees whose DBH are close to the stand mean DBH in the plot were selected in each sample plot (stand mean DBH: $16.8 \sim 23.1 \mathrm{~cm}$ ). We investigated the amounts of branches per standard tree, and divided one tree into 3 parts: up, middle and down level. One standard branch was extracted in every level to count live larva amounts respectively. Once the larva quantity of one standard branch obtained, live larva number in each level can be obtained through multiplied by number of branches in every level. The total larva amount of one standard tree can be gained by sum of three levels' live larva number. Moreover, variables were recorded in one plot, which describe the characteristics of injury and environmental factors: (1) PD, population density (amount of pests in one standard tree), (2) PIIT (percentage of insect-infected trees (\%)), (3) environmental factors: GPS of plots location, elevation, aspect, slope, tree height, forest canopy density, stand age, tree species composition and stand density. Several temporary sample plots would be settled if requirements of considering different environmental factors. Research of vertical distribution regularity in host crown of Pristiphora laricis is also studied. Ten sample trees were selected to investigate the pest in the study site. Sample branch were also selected in up, middle and down level in one tree separately to count live larve number, and then each level live larva amount was obtained with the help of sample branch multiplied by number of branches in every level.

Other auxiliary data were also collected, including the infectious area (hectares) of Pristiphora laricis every year (statistics in EXCEL), time ranging from 1992 to 2007 (2001 not happened) provided by Saihanba Mechanical Forest Farm which are located in longitude $117^{\circ} 14^{\prime} \mathrm{E}$, and latitude $42^{\circ} 15^{\prime} \mathrm{N}$, with elevation $1506 \mathrm{~m}$. According to the standard of damage division from the farm, 1500-2000 larve per tree is mild damage. 2001-3500 larve per tree is moderate damage and above 3501 larve per tree is severe damage. The infectious area of Pristiphora laricis every year includes mild, moderate and severe damage.

The scale of topographic map is 1:50, 000, which were provided by local forestry authority, being used to do geometric correction and extract road line. The forest resource inventory data in 2005 in the study area, the land use type map, pests disaster distribution map of Pristiphora laricis provided by local forestry authority were collected for GIS analysis and modeling.

The remotely sensed data used for this project is 20-m multispectral CBERS-02 data which were provided by China Centre for Resources Satellite Data and Application. CBERS-01 and 02 are identical satellites. They have three remote sensing multispectral cameras: Wide Field Imager Camera (WFI), Medium Resolution Camera (CCD) and Infrared Multispectral Scanner Camera (IRMSS). More detail is coming from http://www.cbers.inpe.br. The image in our study was collected on September 16, 2006. Visible and near infrared bands of CCD cameras data were used to monitor the occurrence of Pristiphora laricis pest.

\section{Data preprocessing}

First, the relationship between pest occurrence area and habitat factors were processed and analyzed in SPSS software, mainly using correlation analysis and variance analysis which are in common use in statistic analysis. So we mainly chose the infected area, PIIT, and PD as the dependent 
variables to explore the relationship with other ecological factors, including topographical factors and forest stand factors.

After preliminary analysis, twelve points taken from topographic maps at 1: 50, 000 scale (Gaussian-kriging projection and Krassovsky spheroid with central meridian $117^{\circ} \mathrm{E}$ ) were used to make geometrical rectification and registration by using a nearest neighbor resampling technique. A root-mean-square error is 0.487 pixels. An improved image-based object subtraction model was used to implement atmospheric correction. The gain and offset for each band and sun elevation angle were obtained from image header file, and the path radiance was identified based on clear water for each band. The atmospheric transmittance values for visible and near infrared bands were the averages for each spectral band derived from radiative transfer code [23], [24], [25]. Than the processing of remote sensing data and the extraction of NDVI were calculated by Erdas Imagine and ENVI.

Secondly, information load method was mainly implemented by overlay analysis in ArcGIS. However, it is hardly implemented without the support of spatial database. So we transformed the format of various data in EXCEL into grid layer in ArcGIS as model input data. Because the sample data was acquired from the spatial domain and GIS is a tool for spatial data processing, display and analysis, using the information load method to calculate the result of GIS's data entry and display the results in GIS environment, it can achieve the goal of combination between information load method and GIS technique. So according to the principle of information load method, GIS is a good approach to apply the idea of information load in analyzing pest's infection situation and mapping. For the purpose of calculating $\mathrm{N}_{\mathrm{i}} / \mathrm{S}_{\mathrm{i}}$, using the spatial analysis model of ArcGIS in ArcGIS 9.3 environment, data was divided into two basic data type: grid data and vector data. Considering the convenience of expressions of grid data like NDVI, aspect, DEM etc, we converted all data, including topographical data, pest infection area into uniform grid layers with grid size of $20 * 20 \mathrm{~m}$ as environmental factor layers. The total amount of raster unit can be easily calculated by statistics in ArcGIS. In the Raster Calculator of ArcGIS, each factor layer would multiply pests disaster distribution map of Pristiphora laricis to get a new distribution map of Pristiphora laricis pests condition. According to the attribute sheet in ArcGIS, we can get various condition of distribution of this factor layer of Pristiphora laricis disaster. Twenty ground control points which are characterized by roads crossing or rivers crossing were selected. Raster layers are of unified projection coordinate (Gaussian-kriging projection and Krassovsky spheroid) with central meridian $117^{\circ} \mathrm{E}$ and grid unit $(20 \mathrm{~m} * 20 \mathrm{~m})$. Slope, aspect, elevation raster data were obtained from DEM, which is converted from TIN by executing spatial analysis process in ArcGIS's spatial analyst module. The vectorial contour layer that were extracted from topographic map, whose contour interval is $10 \mathrm{~m}$, were converted to TIN utilizing 3D Analyst Model in ArcGIS. The computer software we used include: SPSS 13.0, ArcGIS 9.3, Erdas Imagine 9.2 and ENVI. SPSS was used for data statistic. DEM and topographic factors' extraction and spatial analysis were implemented by ArcGIS. In practice the impact of some factors to pest disaster will not increase proportionally entirely according to the increase of the amount of factors, but within some number range it is stable, therefore, requires re-classification to parts continuous data. It was mainly accomplished by reclassifying the order in spatial analysis model in ArcGIS. In information load method, it also need to re-classify factors maps according to information load in parameter list.

Modeling method and accuracy assessment

The key point of building of forecast model is having enough sampling data. Although we tried our best to collect enough data, the sampling data we collected still limited. The number of sample statistics were often restricted, so the simplified information load model were used, specifically using conditional probability to calculate the information load and make comprehensive overlay analysis at last. The followed is the simplified information model. 


$$
I=\sum_{i=1}^{n} I_{i}=\sum_{i=1}^{n} \lg \frac{N_{i} / N}{S_{i} / S}
$$

In the equation,

$I$ presents the information load of predicting value of some unit in study area.

$I_{i}$ presents the information load providing by factor $x_{i}$ for the occurrence of pest.

$S$ presents the total area.

$S_{i}$ presents the total area of the unit including factor $x_{i}$.

$N$ presents the total area of the unit where pest disaster had already occurred.

$N_{i}$ presents the total area of the unit where pest disaster had already occurred but including factor $x_{i}$.

By calculation, it could obtain the comprehensive evaluation of information load $I$ in each dividing unit. The greater the value was indicated that more possibility of the occurrence of pest disaster in the unit was.

Put each factor layer's attribution table and corresponding attribution table of each factor layer that was multiplied by pests disaster distribution map of Pristiphora laricis into Excel table. The information load of various type of each layer was calculated by the following formula computing:

$$
I=\sum_{i=1}^{n} I_{i}=\sum \lg \frac{N_{i} / N}{S_{i} / S}=\sum \lg \frac{N_{i} / S_{i}}{N / S}
$$

$N$ presented the total number of the unit where pest disaster had already occurred.

$S$ presented the total number in study area.

The $\mathrm{S}$ represents total 61086 pixels and the number of raster units with the pest disasters which has already happened over the years is 14731. After all kind of information load in each factor layer being worked out, we could add the value of raster corresponding different layers, mainly using spatial raster calculator in ArcGIS software. The final result was a comprehensive information load map in the whole study area, and it also can be named pests disaster danger score plot which listed the range of information load. The greater the value is, the bigger the contribution rate of very kind factor to the occurrence of Pristiphora laricis pest disaster is and more dangerous the occurrence of Pristiphora laricis pests disaster is.

After calculating the information load of different states of each factor, it could obtain information load raster layers of different factor layers. So called spatial surface processing of information load will be implemented, and being saved as ESRI GRID format. Then use spatial raster calculator provided by ArcGIS to do cumulative operation to corresponding grids of different factor layers. And then integrated information map of all elements could be finished. Lastly, natural interrupt which is commonly used in statistical method, was used to reclassify the risk score map, and it was divided into 5 levels which are most serious degree, serious degree, moderate degree, mild degree and non-hazard degree.

Accuracy assessment formula is as follows:

$$
P=\frac{M}{N} \text {. }
$$

In the formula, $\mathrm{M}$ represented the number of grid cells falling in most serious degree and serious degree areas. $\mathrm{N}$ represented the total number of grid cells of Pristiphora laricis. The grid cell number of each risk degree was obtained from ArcGIS. 


\section{Result Analysis}

Analysis of impacts of forest related factors on PIIT and PD

Pure larch stands is the main trees in study site, with a little component of Pinus sylvestris, Birch, Oak trees mixed forest. Three sample plots in every level (pure forest level and mixed forest level) were selected to investigate PD and PIIT.

Table 1. Comparison of the population density of Pristiphora laricis in pure or mixed stands

\begin{tabular}{ccccl}
\hline $\begin{array}{c}\text { Investigation } \\
\text { site }\end{array}$ & $\begin{array}{c}\text { Tree } \\
\text { composition }\end{array}$ & $\begin{array}{c}\text { Percentage of } \\
\text { insect-infected } \\
\text { trees }\end{array}$ & $\begin{array}{c}\text { Population density } \\
\text { (per tree) }\end{array}$ & Note \\
\hline \multirow{2}{*}{ Moon lake } & Pure forest & 100 & 3350 & Pure larch stands, with grass on the groud \\
Xiaoqiaozi & Pure forest & 100 & 4310 & \\
& Pure forest & 100 & 2765 & Larch forest mixed with white birch forest, \\
& Mixed forest & 75.0 & 136 & with grass and shrub \\
\hline
\end{tabular}

The result of variance analysis shows that the composition proportion of trees can observably affect population density and percentage of insect-infected trees. The harm to larch forest by Pristiphora laricis is much higher in pure forests than in mixed forests. The reason is that pure forest biophysical structure is relative simple than mixed forest, because of less ground cover, simple food chain, and poor regulation capacity of ecosystem. Mixed forest, especially multilevel pine and broadleaves mixed plantation, having characteristics of high crown density, low light, low temperature and high humidity, is not favorable for the development of the pests.

We investigated the larch forest density, conopy density, population density and percentage of insect-infected trees in four larch forests in the Yueliang Lake. It presents negative correlation between forest density and population density, so as conopy density to population density. Pristiphora laricis prefer eating mature forests to eating young and middle-age forest (Table 2).

Table 2. The relationship between the population density and stand density, crown closure

\begin{tabular}{cccc}
\hline No. & Stand Density(trees/hm2) & Canopy Density & population density (per tree) \\
\hline I & 750 & 0.5 & 4310 \\
II & 975 & 0.6 & 3850 \\
III & 1035 & 0.7 & 3350 \\
IV & 1350 & 0.8 & 2653 \\
\hline
\end{tabular}

Table 3. Comparison of the population density of Pristiphora laricis with different ages

\begin{tabular}{cccc}
\hline Investigation site & Stand age & Population density (per tree) & Degree \\
\hline XiaoQiaozi & Young forest & 0 & Health \\
GeDaqiaobei & Middle age & 1320 & Little Damage \\
Moon lake & Mature forest & 3593 & Moderate or serious \\
\hline
\end{tabular}

10 sample trees were investigated, and total larva amount is 50322, which is $56.73 \%$ in low level, 30 . $13 \%$ in middle level and only $13.14 \%$ in upper level. The number of larve in lower level is much more than that of in middle and upper level. Partly because mature larva will overwinter as the prepupa in the litter layer after going down the tree, the adult emergence would be in late July and 
early August next year and lay eggs. The more branches close to the ground, the more opportunity the adult lavrve would lay eggs on the back of needle and the more number of eggs that would hatch to larve. So the majority of live larve stay in the lower part of tree. The result of variance analysis shows that the amount of live larva in the three parts of one larch tree has significantly difference.

Table 4. Vertical distribution of the number of larvae in the tree crown

\begin{tabular}{ccccc}
\hline \multirow{2}{*}{ Investigation site } & \multirow{2}{*}{ No. Sample tree } & \multicolumn{3}{c}{ The amount of larvae } \\
\cline { 3 - 5 } & 1 & Upper layer & Middle layer & Lower layer \\
\hline \multirow{3}{*}{ Moon lake } & 2 & 722 & 3184 & 5686 \\
& 3 & 656 & 1538 & 4877 \\
& 4 & 1430 & 3216 & 5432 \\
& 5 & 600 & 950 & 1800 \\
XiaoQiaozi & 6 & 736 & 1324 & 2250 \\
& 7 & 220 & 752 & 1700 \\
& 8 & 315 & 660 & 1321 \\
& 9 & 404 & 738 & 1400 \\
& 10 & 180 & 575 & 1060 \\
\hline
\end{tabular}

Note:1-4 sample tree is forest edge beside roads. 5-6 is inside and 7-10 is forest edge

Table 5. Table of variance analysis

\begin{tabular}{cccccc}
\hline \multirow{2}{*}{ Variation Sources } & \multicolumn{5}{c}{ Result } \\
\cline { 2 - 6 } & Sum of Squares & df & Mean Square & F & Sig. \\
\hline Between Groups & 24460639 & 2 & 12230319.70 & 8.193 & 0.002 \\
Within Groups & 40303200 & 27 & 1492711.104 & & \\
sum & 64763839 & 29 & & & \\
\hline
\end{tabular}

F0. $05(2,27)=3.4$

The occurrence of Pristiphora laricis has a strong altitude distribution characteristic. As the altitude increased, the amount of occurrence and extent of the harm has been strengthened. It can be concluded that trend of the pests occurrence spreads to the higher altitudes. 10 sample trees in temporary sample plots were selected in different parts of mountain in same place. The result of investigation shows that the amount of the pest population would be different as the difference of the mountain part. The population density in ridge was more serious than it in valley (15\% higher), while difference of percentage of insect-infected trees was insignificant. It was also found that population density of Pristiphora laricis in sunny slope was higher than it in shady slope.

Calculation and analysis of information load method

Prior to this section, the relationship between the occurrence of Pristiphora laricis and environmental factors had been studied. The results showed that the occurrence of Pristiphora laricis had close relationship with terrain, stand factors, distribution of host and so on. First variable factor is elevation. Table 6 shows information load contribution to the disaster of Pristiphora laricis calculated from elevation variables. When the value of calculated information load was above zero, it showed that the corresponding factor had contribution to the formation of Pristiphora laricis disaster. When it was less than zero, it showed that it had little contribution to the formation of Pristiphora laricis disaster. $\mathrm{N}_{\mathrm{i}}$ is infected area. $\mathrm{S}_{\mathrm{i}}$ is environmental factor area. $\mathrm{I}_{\mathrm{i}}$ is information load value (Note: area of factors could be replaced by the raster grid amount). 
Table 6. Information load between altitude and infected area of Pristiphora laricis

\begin{tabular}{lllll}
\hline $\begin{array}{l}\text { Elevation } \\
\text { Range }(\mathrm{m})\end{array}$ & $N_{i}$ & $S_{i}$ & $I_{i}$ & $\begin{array}{l}\text { Variable } \\
\text { Name }\end{array}$ \\
\hline $1450 \sim 1500$ & 96 & 2192 & -0.74 & $\mathrm{X} 1$ \\
$1500 \sim 1550$ & 185 & 2608 & -0.53 & $\mathrm{X} 2$ \\
$1550 \sim 1600$ & 388 & 4334 & -0.43 & $\mathrm{X} 3$ \\
$1600 \sim 1650$ & 1883 & 13976 & -0.25 & $\mathrm{X} 4$ \\
$1650 \sim 1700$ & 7782 & 28932 & 0.05 & $\mathrm{X} 5$ \\
$1700 \sim 1750$ & 3607 & 7578 & 0.30 & $\mathrm{X} 6$ \\
$1750 \sim 1800$ & 775 & 1445 & 0.35 & $\mathrm{X} 7$ \\
$>1800$ & 15 & 21 & 0.47 & $\mathrm{X} 8$ \\
Total & 14731 & 61086 & & \\
\hline
\end{tabular}

Second one is land use types. Calculating information load of the occurrence of Pristiphora laricis need take each type of land into account. According to the pest's biological characteristics and occurrence regularity (the host of Pristiphora laricis's infection is larch, doing no harm to other trees), there would be no infected area which distributs in open forest land, shrub forest, immature forest, barren hills and non-forest land in the study area (in a total of 18895 grid cells). So the contribution to the occurrence of Pristiphora laricis from these land types was zero. It especially damaged pure larch forest, including small amount of mixed forest of larch and white birch.

Table 7. Classification on different damaged degrees based on information load model

\begin{tabular}{ll}
\hline Risk Degree & Information load In The Grid ${ }^{I}$ \\
\hline None & $-3.38<{ }^{I_{i}}<-2.09$ \\
Light & $-2.09<{ }^{I_{i}}<-1.41$ \\
Moderate & $-1.41<{ }^{I}{ }<0.09$ \\
Severe & $0.088<{ }^{I}<0.73$ \\
Very severe & $0.73<I_{i}<1.55$ \\
\hline
\end{tabular}

The information load of elevation shows that, the elevation of the occurrence of Pristiphora laricis mostly ranges from 1650 to $1800 \mathrm{~m}$. Slope information load shows that, Pristiphora laricis infection would be more likely to happen in gentle slope terrain (The slope was less than $15^{\circ}$ ). Aspect information load shows that Pristiphora laricis would be more likely to happen in sunny slope $\left(135^{\circ}\right.$ $\sim 270^{\circ}$ ). Land use types information load shows that, it is mainly damaging larch pure forest. Larch mixed forest would be destroyed slightly. Road buffer analysis information load shows that, it is more likely to infect the pest nearer to the road (the way to the Saihanba farm). That is to say, the occurrence is more serious in the edge of the forest than inside. NDVI information load shows that most of the Pristiphora laricis disaster occurs in the range of vegetation index NDVI value between 
0.6 and 0.7. We have to cut down some tables of other environmental factors owing to the paper space reason, including slope, aspect, Land Using Type and NDVI.

Generation of Comprehensive information load map

After calculating the information load of different states of each factor, it could obtain information load raster layers of different factor layers. And then integrated information map of all elements could be finished by combining every different factor layers using spatial raster calculator provided by ArcGIS doing cumulative operation. It is risk score map of the occurrence of Pristiphora laricis disaster (Look at Figure 2). The table 7 shows that the higher the value is, the greater the contribution rate to Pristiphora laricis disaster from various factors is, and the greater the risk of occurrence comes.

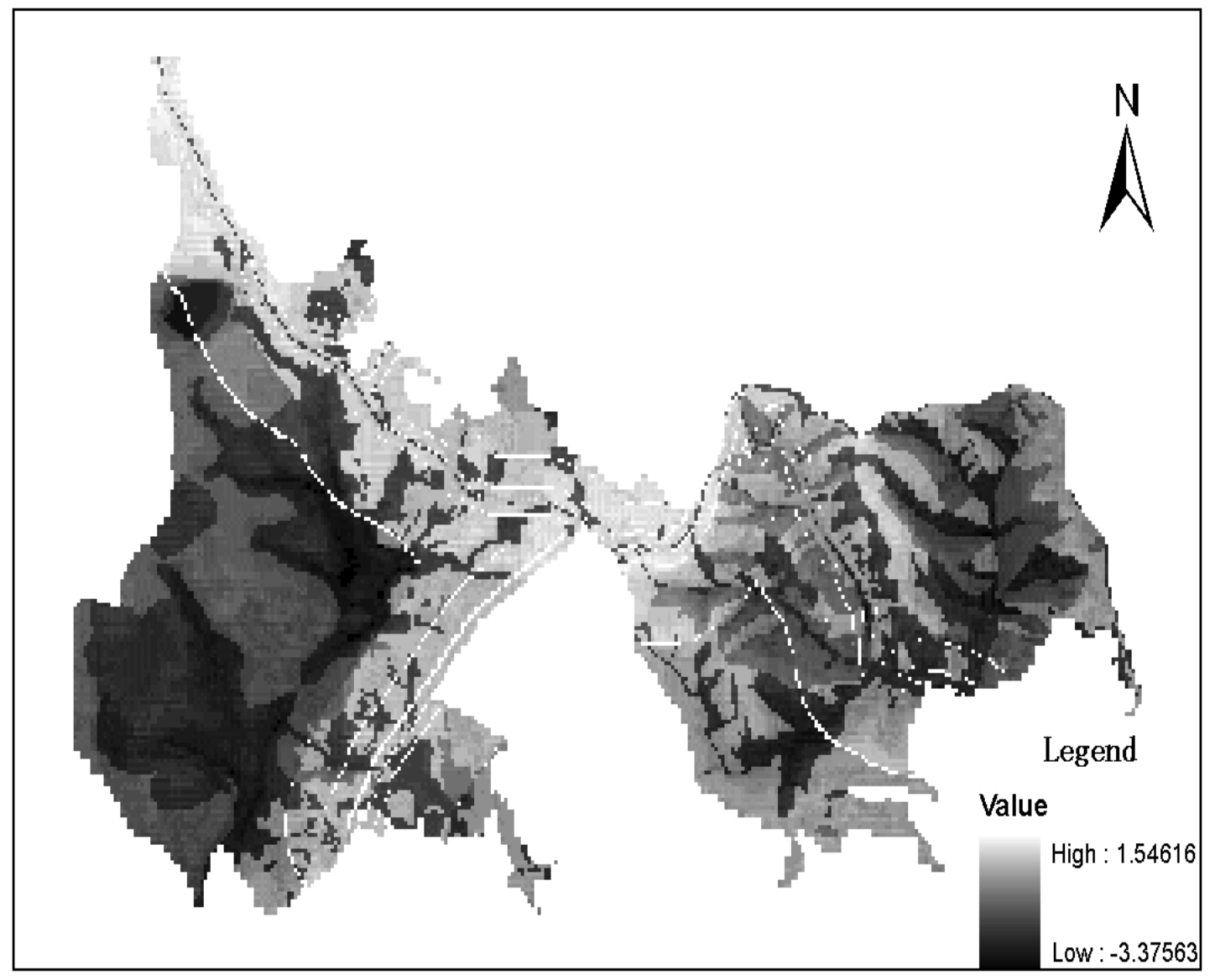

Figure 2. The prediction map based on information load model

In order to be convenient to distinguish the varying degrees of risk, reclassify the total information load map to distinguish different levels of risk of Pristiphora laricis disaster. Without uniform standard for classification, the passage used the method of called natural interrupt which is commonly used in statistical method, to reclassify the risk score map, and it was divided into 5 levels, most serious degree, serious degree, moderate degree, mild degree, non-hazard degree.

The principle of reclassification is to ensure the accordance between the classifying levels and previous collected pest distribution map of Pristiphora laricis as much as possible, comparing the calculated total information load map with original distribution map of Pristiphora laricis disaster situation. According to Table 7, reclassification hazard score map of Pristiphora laricis disaster and generation of hazard distribution raster map of Pristiphora laricis disaster suggested that the disaster in the red part of study area is more likely to happen (See Figure 3) and mainly distribute in the area of 
both sides of the road to the headquarters of Saihanba Mechanical Forestry Farm. And in the DongDaLiang forest area and the BeiCha forest area, Pristiphora laricis disaster also occured scatteredly.

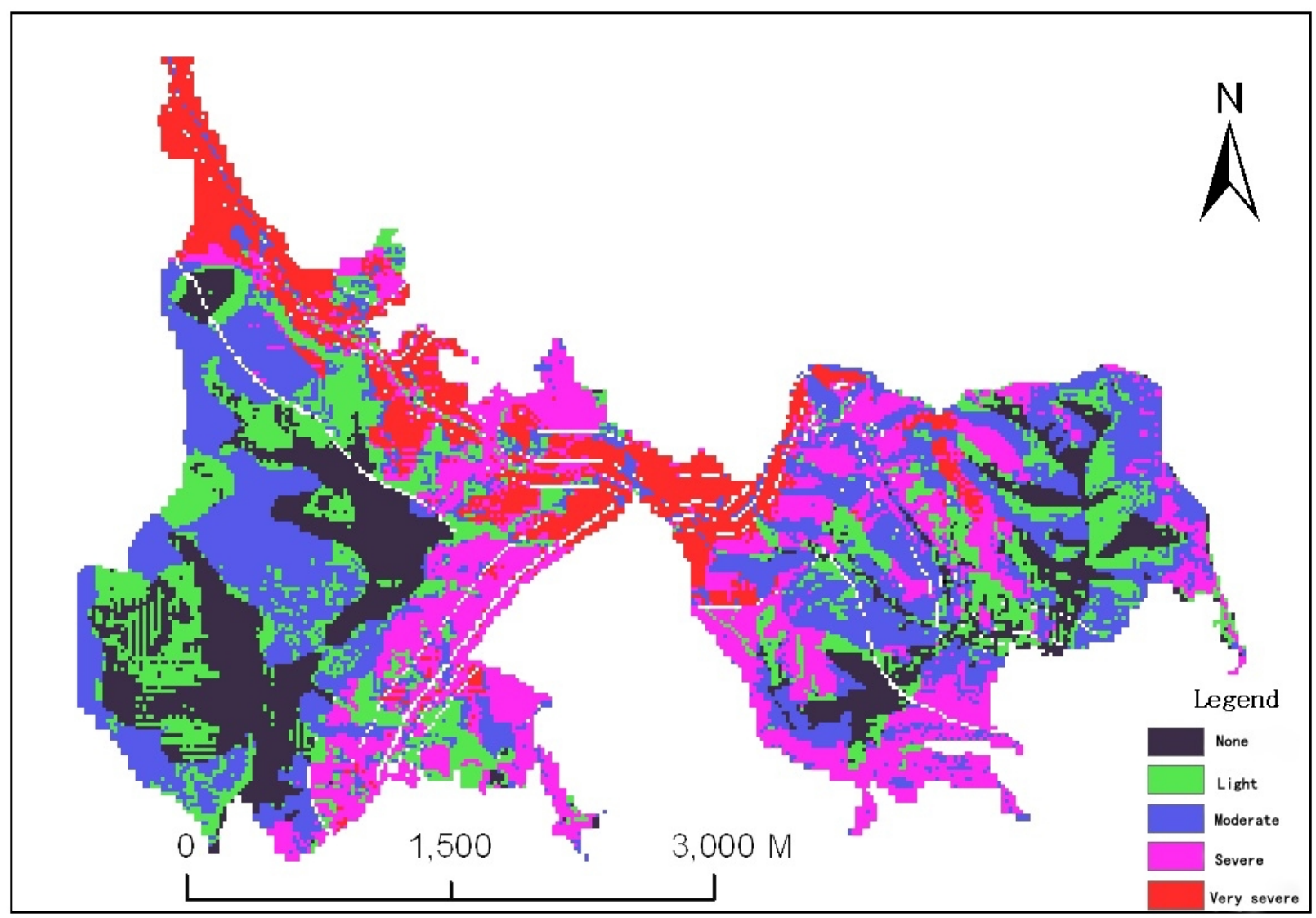

Figure 3. Raster map of the hazard of Larix principis-rupprechtii on different damaged degrees

In the accuracy assessment formula, $\mathrm{M}$ represents amount of grid cells falling in most serious degree and serious degree areas. $\mathrm{N}$ represents the total number of grid cells of Pristiphora laricis. In the risk degree map obtained by information load method, areas of most serious degree and serious degree occupy $83.1 \%$ of the total area of Pristiphora laricis disaster, and the prediction accuracy of information model method achieved $83.1 \%$, indicating that the model had high prediction accuracy and could be used for predictive analysis.

\section{Discussion}

Pest occurrence is an extremely complex research topic and, what's more, among many environmental factors there were mutual influence, mutual restriction and interaction such as climatic factors[26, 27]. We should have also taken into account more factors such as meteorological factors when modeling the pests' spread. In fact, in this paper, the meteorological data we collected from 1992-2007 appears a certain trend for modeling of the impacts of ecological factors. It is apparently that pest disasters are caused by integrated impact from various environmental factors. However, because of the reasons for data acquisition and modeling, it didn't consider other more influencing factors to the occurrence of the pest, such as climatic factors, human factors (control measures) which also played important roles in the occurrence of Pristiphora laricis disaster. Meteorological factors should be included in future research.

The predicted classification of Pristiphora laricis attack stages using GIS information load method presented challenges that led to our development of new methodological techniques to 
achieve high accuracy. In the process of GIS-information load analysis, each quantitative variable was divided into different levels by man-made method which produces certain negative effect on the result of calculation. So called natural interrupt method in the process of the last information load mapping indirectly decided the pest infection area, thus it would affect the accuracy assessment. Have to say that, we analyzed the relationship between pest's infestation area and environmental factors, such as topographic factors, and human factors, at the processing of analysis of using GIS-information load method. However, not all factors we analyzed above were taking part in modeling of GIS-information load. The considered factors are the road factor, land use type, NDVI, DEM, Slope, and Aspect. In the previous studies many scientists have done researches about the relationship between meteorological data and pests' occurrence. Gaëlle Rouault [28] wrote that drought in western and central Europe in 2003, becomes a prominent and primary cause of the development of pest outbreaks. Global change will have demonstrable changes in the frequency and intensity of pest outbreaks, particularly at the margins of host ranges [29]. Different place have different dominant factors.

The way of data calculation in paper could not meet the need for hazard analysis fully. It need to directly make secondary development in GIS in the future, and develop some more complex algorithms (such as logistic regression evaluation model) directly embedded in GIS environment as functional modules in GIS to execute quantitative evaluation without data flowing out of GIS platform. In the last process of accuracy analysis, the prediction accuracy $83.1 \%$ only show consistency with infected area in numbers and it does not reflect the spatial distribution of the pest infection. Our original intention using the information load method with GIS is to implement quantitative forecast on the domain of space. Through exploring the environmental factors affecting pest's infection, including direct and indirect influence, analyzing the correlations, selecting factors that are of higher coefficient of correlation as modeling independent variables. The reasonable accuracy analysis should be proceeded to compare the pest's infected area of different years with the result of the raster map of Pristiphora laricis disaster. Because of the limit of data collecting, the time series analysis about the pest's infection condition have not been considered in the study.

The information load model using GIS technology can quantitatively predict Pristiphora laricis disaster. According to the results of information load method, the area was divided into 5 grades in the distribution map of risk degree. In Figure 3, highest-risk and high-risk areas represented the possible spatial location of the occurrence of Pristiphora laricis disaster. The prediction results provided scientific method for the prevention and treatment to the pest. The prediction accuracy of information load model method arrived $83.1 \%$, which indicated that the model had high prediction accuracy and could be used for predictive analysis. The specific classification method was natural interrupt method. The advantage of this is that it could make information load of factors keep generally consistent, and make the information load of different classes varying greatly, so that it could reflect spatial difference of occurrence probability of Pristiphora laricis. Overall, because of the reasons of the response of pests themselves to the environment and the frequent human activities and so on, the risk was high in the area of both sides of the road to the headquarters of Saihanba Mechanical Forestry Farm. Forest stand and terrain factors closely related to the occurrence of the pest, performing heavier in pure forest than in the mixed forest, open forest heavier than thick forest, forest edge heavier than inside forest, mature forest heavier than young forest, the host's lower part heavier than middle and upper part, high-altitude areas heavier than low-altitude, sunny slope heavier than shady slope, mountain ridge heavier than the valley. Human activity factor (control measures) can significantly reduce the population density of the larva. Maintaining and increasing biodiversity level especially in pure plantations is one important way to improve the resistance of 
forests to pests in Chinese boreal forests [31]. The extent of the current Pristiphora laricis outbreak and the associated economic impacts, have prompted research into new techniques and data sources for reconnaissance and mapping of the infection. Management efforts at the local level have shifted from attempting to address all levels of infection across the landscape, to the detection and mitigation of sites with minimal levels of infection. Detection and mapping of current impact enables planning and mitigation activities, and serves as a driver for parameterizing models of the pest which are designed to reduce future risks and impacts [30].

GIS and RS have become more popular in the study of pests detection and mitigation. GIS provides environment for modeling, and RS provide important parameter as a vital data source. The combination of RS, GIS, and GPS technology has great potential and vast development prospects. Especially, high spatial resolution RS image, such as QuickBird, IKONOS, GeoEye et al., can provide high accuracy mapping and detection because of the sub-meter pixels. Some researches indicate that it could increase the accuracy of mapping and reasonability on evaluation of prediction precision.

\section{Conclusion}

The harm to larch forest by Pristiphora laricis is much higher in pure forests than in mixed forests. Mixed forest can effectively prevent the infection of the pest. Negative correlation between forest density and population density, conopy density and population density exists. It prefers eating mature forests to eating young and middle-age forest. The amount of live larva in the three parts of one larch tree has significantly difference. The population density in ridge is more serious than it in valley (15\% higher), while difference of percentage of insect-infected trees was insignificant. Population density of Pristiphora laricis in sunny slope was higher than it in shady slope. Finally, the prediction accuracy of information load model method arrived $83.1 \%$, indicating that the model had high prediction accuracy and could be used for predictive analysis. The study gives new idea to improve the integrated pest management (IPM).

\section{Acknowledgements}

This research was funded by The National Natural Science Foundation of "Multi-agent simulation and spatial prediction of the invasion and the spread of forestry alien pests" (30871964). We thank all group members for hard work.

\section{References}

[1] W.A. Kurz, M. Apps, E. Banfield and G. Stinson: Forest carbon accounting at the operational scale. The Forest Chronicle Vol. 672-679 (2002), P. 78

[2] J.H.M. Arjan, A.H. Jeffrey: Evaluating the potential of multispectral imagery to map multiple stages of tree mortality. Remote Sensing of Environment Vol. 1632-1642 (2011), P. 115

[3] W.A. Kurz, C.C. Dymond, G. Stinson, G.J. Rampley, E.T. Neilson, A.L. Carroll, T. Ebata, and L. Safranyik: Mountain pine beetle and forest carbon feedback to climate change. Nature Vol. 987-990 (2008), P. 452

[4] R.R. Nemani, C.D. Keeling, H. Hashimoto, W.M. Jolly, and S.C. Piper: Climate-driven increases in global terrestrial net primary production from 1982 to 1999 . Science Vol. 1560-1563 (2003), P. 300

[5] L. Huang, Z.Y. Ning and X.L. Zhang: Impacts of caterpillar disturbance on forest net primary production estimation in China. Ecological Indictor. Vol. 1144-1151 (2010), P. 10

[6] B.C. Sam, C.C. Nicholas, A.W. Michael: Estimates of bark beetle infestation expansion factors 
with adaptive cluster sampling. International Journal of Pest Management.Vol. 11-21 (2010), P. 57

[7] H.Y. Pan: Problems and countermeasures in forest pests prevention in China. Forest Pest and Disease. Vol. 89-92 (2002), P. 28: (in chinese).

[8] S.M. Zhang, X.Y. Huang and S.Z. Zhou: The study on two larch sawfly. Forest Research. Vol. 518-523 (1990), P. 3 (in chinese).

[9] M.L. Li, Z.Y. Tang and Y.Q. Song: The study on biological character and occurrence rules of larch sawfly. Journal of Northwest Forestry College. Vol. 30-33 (1994), P. 9 (in chinese).

[10] V.C. Radeloff, D.J. Mladenoff, M.S. Boyce: Effects of interacting distrbances on landscape patterns: budworm defoliation and salvage logging. Ecological Applications. Vol. 233-247 (2000), P. 10.

[11] V.C. Radeloff, D.J. Mladenoff and M.S. Boyce: Detecting Jack Pine Budworm defoliation using spectral mixture analysis: separating effects from determinants. Remote Sensing of Environment. Vol. 156-169 (1999), P. 69

[12] S.E. Franklin, A.G. Raske: Satellite remote sensing of spruce budworm forest defoliation in western Newfoundland. Canadian Journal of Remote Sensing. Vol. 30-48 (1994), P. 20

[13] S.E. Franklin, M.A.Wulder and R. Skakun, A. Carroll: Mountain pine beetle redattack forest damage classification using stratified Landsat TM data in British Columbia, Canada. Photogrammetric Engineering and Remote Sensing. Vol. 283-288 (2003), P. 69

[14]R.S. Skakuna, M.A. Wulder and S.E. Franklin: Sensitivity of the thematic mapper enhanced wetness difference index to detect mountain pine beetle red-attack damage. Remote Sensing of Environment. Vol. 433-443 (2003), P. 86

[15]R. Lawrence, M. E. Labus: detection of Douglas-fir beetle infection with subcanopy resolution hyperspectral imagery. Western Journa of Applied Forestry. Vol. 202-206 (2003), P. 18

[16]E.E. Berg, J.D. Henry, C.L. Fastie and A.D. Volder and S.M. Matsuoka: Spruce beetle outbreaks on the Kenai Peninsula, Alaska, and Kluane National Park and Reserve, Yukon Territory: relationship to summer temperatures and regional differences in disturbance regimes. Forest ecology and Management. Vol. 219-232 (2006), P. 227

[17]P.E. Joria, S.C. Ahearn and M. Gonnor: A comparison of the SPOT and landsat thematic mapper satellite systems for detecting gypsy moth defoliation in Michigan. Photogrammetric Engineering and Remote Sensing Vol. 1605-1612 (1991), P. 57

[18] V.I. Kharuk, K.J. Ranson and V.V. Kuzmichev: Landsat-based analysis of insect outbreaks in southern Siberia. Canadian Journal of remote sensing Vol. 286-297 (2003), P. 29

[19] J.Y. Wu, J. Ni: Spectral characteristics of the pine leaves damaged by pine moth and a model for detecting the damage early. Journal of Remote Sensing Vol. 250-258 (1995), P. 10 (in Chinese).

[20] Y.H. Luo, L.Zhang and Y.C. Zhang, in: Risk Assessment of Geological Disasters, edited by Geological Publishing House, Beijing (1998) (in Chinese).

[21]S.Y. Ruan, R.Q. Huang: Application of GIS-based information model on assessment of geological hazards risk. Journal of Cheng Du University of Technology Vol. 89-92 (2001), P. 28 (in Chinese).

[22]Q.S. Wang, Y.Z. Li and D.S. Lu: Analysis on transitional feature of Saihanba spermatophyte flora in Hebei Province. Chinese Journal of Ecology Vol. 473-477 (2005), P. 24 (in Chinese).

[23]D. Lu, P. Mausel, E. Bronadizio and E. Moran: Assessment of atmospheric correction methods for Landsat TM data applicable to Amazon basin LBA research. International Journal of Remote Sensing Vol. 2651-2671 (2002), P. 23

[24]D. Lu, M. Batistella and E. Morran: Satellite estimation of aboveground biomass and impacts of forest stand structure. Photogrammetric engineering and remote sensing Vol. 967-974 (2005), P. 71

[25]P.S. Chavez: Image-based atmospheric corrections-revisited and improved. Photogrammetric Engineering and Remote Sensing Vol. 1025-1036 (1996), P. 62

[26]C.Y. Liu, L. Li and X.H. Zhao: Redistribution effects of tree canopy of Larix princip is-rupprechtii plantation on precipitation in the upper stream of saihanba area. Journal of 
Northwest Forestry University Vol. 1-5 (2010), P. 26 (in chinese).

[27]C.Y. Liu, J.C. Gu and J.Y. Li: Correlated analysis between the growth of Larix principis-rupprechtii and climatic factors in Saihanba Nature Reserve, northern Hebei province. Journal of Beijing Forestry University Vol. 102-105 (2009), P. 31 (in chinese).

[28] G. Rouault, J.N. Candau and F. Lieutier: Effects of drought and heat on forest insect populations in relation to the 2003 drought in Western Europe. Annals of Forest Science Vol. 613-624 (2006), P. 63

[29] W.J.A. Volney, R.A. Fleming: Climate change and impacts of boreal forest insects. Agriculture, Ecosystems and Environment Vol. 283-294 (2000), P. 82

[30]C.W. Joanne, A.W. Michael and B. Darin: Detection of red attack stage mountain pine beetle infestation with high spatial resolution satellite imagery. Remote Sensing of Environment Vol. 340-351 (2005), P. 96

[31]J. Li, J. Shi and Y.Q. Luo: Plant and insect diversity along an experimental gradient of larch-birch mixtures in Chinese boreal forests. Turkish Journal of Agriculture and Forestry Vol. 247-255 (2012), P. 36 
